\title{
Alegações sobre mídia digital no âmbito da lei federal 10.639/2003, Consciência linguística crítica e formação docente
}

\section{Considerations about digital media within the framework of federal law 10.639/2003: Critical language awareness and teacher training}

\section{Carlos José Lirio* UNIFESP}

Resumo: Este estudo tem como principal objetivo apresentar algumas alegações de caráter crítico-discursivo sobre como as vias midiáticas digitais podem favorecer a formação de professoras(es) no âmbito da Lei Federal 10.639/2003 e de suas Diretrizes Curriculares. Em razão da natureza transdisciplinar deste estudo, o quadro teórico selecionado traz, de um lado, um aparato advindo das pesquisas sobre mídia digital (PERNISA JÚNIOR; ALVES, 2010) e, de outro lado, os conhecimentos acerca de (multi)letramentos (STREET, [1995] 2014; MOITA-LOPES, 2012; PINHEIRO, 2012). Além do referido arcabouço teórico são, também, mobilizados conhecimentos relativos à diversidade étnico-racial e educação (GOMES, 2005, 2007). A abordagem teórico-metodológica utilizada para articular os arcabouços mencionados e alcançar o que aqui se pretende pode ser caracterizada como crítico-discursiva (FAIRCLOUGH, 2009; CHOULIARAKI; FAIRCLOUGH, 1999). Nesse sentido, uma decorrência didático-pedagógica de caráter crítico-discursivo seria, por exemplo, a consideração da relevância de conhecimentos sobre consciência linguística crítica (FAIRCLOUGH, 1992) para uma formação docente (mais) ampla, calcada na vivência de uma ética da linguagem em ambientes virtuais e no reconhecimento da sua necessidade, em especial (mas não somente), no que concerne à educação das relações étnicoraciais.

Palavras-chave: Mídia digital. Consciência linguística crítica. Formação docente. Lei Federal 10.639/2003.

Abstract: This study aims to present some critical-discursive consideration
about how digital media may support teacher training within the framework of
Federal Law 10.639/2003 and its curriculum guidelines. Because of the trans-
disciplinary nature of this study, the theoretical framework that was chosen
brings together research on digital media (PERNISA JÚNIOR; ALVES, 2010)
and also knowledge about (multi)literacies (STREET, [1995] 2014; MOITA-
LOPES, 2012; PINHEIRO, 2012). Apart from the aforementioned theoretical
framework this study also utilizes knowledge about ethnic and racial diversity
in relation to education (GOMES, 2005, 2007). The theoretical-methodological
* Professor do Departamento de Letras da Escola de Filosofia, Letras e Ciências Humanas na Universidade Federal de São Paulo. E-mail: clirio@ unifesp.br 
Alegações sobre mídia digital no âmbito da lei federal 10.639/2003, Consciência linguística crítica e formação docente

approach used to articulate the aforementioned frameworks can be characterized as critical-discursive (FAIRCLOUGH, 2009; CHOULIARAKI; FAIRCLOUGH, 1999). In this sense, a didactic-pedagogical result that was critical-discursive in character would be, for example, a consideration of the relevance of knowledge about critical language awareness (FAIRCLOUGH, 1992) for a broad(er) teacher training, based on the experience of an ethic of language in virtual environments and recognizing its need, especially (but not only), regarding education in relation to ethnic-racial relations.

Keywords: Digital media. Critical language awareness. Teacher training. Federal Law 10.639/2003.

\section{Introdução}

Este estudo tem origem, de um lado, na crescente preocupação (sobretudo nas instituições de ensino superior públicas) com a formação de professores de línguas para a educação das relações étnico-raciais, e, de outro lado, em certos fatos que, quase cotidianamente, são noticiados pela mídia, os quais envolvem questões relativas ao preconceito, à discriminação e à injúria raciais, e, portanto, ao racismo contra afro-brasileiros(as) ${ }^{1}$.

A esfera da formação docente explicita-se quando se consideram as medidas que têm sido tomadas pelo Estado brasileiro para que seja implementada a Lei Federal 10.639/2003, que instituiu a obrigatoriedade do ensino de história e cultura afro-brasileira e africana, assim como da educação das relações étnico-raciais, nos currículos escolares do Ensino Básico. Nesse sentido, diversas ações governamentais, mormente em âmbito federal, foram realizadas, visando propiciar a adequada formação (sobretudo continuada) às (aos) professoras(es) para que possam atuar de acordo com essa exigência legal.

A título de exemplos, menciono, aqui, duas dessas ações estatais que, a meu ver, representam bem tais decisões políticas, as quais, conforme bem lembra Gomes (2007), são frutos da atuação política de alguns parlamentares, da divulgação e publicação dos resultados dos trabalhos de inúmeros pesquisadores (em especial das ciências sociais), mas principalmente da constante reivindicação e pressão social exercida pelo Movimento Negro.

Em abril de 2008, o Ministério da Educação e Cultura (MEC) publicou a Resolução CD/FNDE no 14/08, a qual:

Estabelece critérios para a assistência financeira com o objetivo de fomentar ações voltadas à formação inicial e continuada de professores de educação básica e a elaboração de material didático específico no âmbito do Programa de Ações Afirmativas para a População Negra nas Instituições Federais e Estaduais de Educação Superior (UNIAFRO) (BRASIL, 2008, p. 1).

\author{
${ }^{1}$ Neste estudo não \\ faço uma distinção \\ conceitual entre \\ os termos afro- \\ brasileiros(as), \\ afrodescendentes e \\ negros(as), pois aqui \\ interessa, sobretudo, \\ a referência sócio- \\ histórico-cultural \\ lexicalmente \\ construída, isto é, o \\ fato de que os termos \\ em questão remetem \\ aos(às) brasileiros(as) \\ que descendem \\ dos(as) africanos(as) \\ que vivenciaram \\ a condição de \\ escravos(as).
}


Assim, por meio da Secretaria de Educação Continuada, Alfabetização, Diversidade e Inclusão (SECADI), no contexto do Programa UNIAFRO, foram selecionadas 27 universidades públicas cujos projetos educacionais de formação de professores foram subvencionados pelo governo federal.

Ainda, em junho de 2014, foi estabelecida, no Plano Nacional de Educação, em relação à Meta 13, a seguinte estratégia:

13.4) promover a melhoria da qualidade dos cursos de pedagogia e licenciaturas, por meio da aplicação de instrumento próprio de avaliação aprovado pela Comissão Nacional de Avaliação da Educação Superior - CONAES, integrando-os às demandas e necessidades das redes de educação básica, de modo a permitir aos graduandos a aquisição das qualificações necessárias a conduzir o processo pedagógico de seus futuros alunos(as) (sic), combinando formação geral e específica com a prática didática, além da educação para as relações étnico-raciais, a diversidade e as necessidades das pessoas com deficiência (BRASIL, 2014, p. 50, grifo meu).

Já a esfera midiática evidencia-se quando são noticiados fatos relativos à educação, à publicidade, ao esporte e ao cotidiano de modo geral, informando sobre indivíduos e/ou grupos que sofrem preconceito, discriminação e injúria raciais, ignomínias que, somadas, dão concretude ao racismo existente na sociedade brasileira, neste estudo, em especial, contra os(as) afrodescendentes.

Nesse sentido, parecem-me representativas as seguintes matérias jornalísticas que recentemente circularam na mídia brasileira:

(01) Universidade Federal do Espírito Santo afasta professor acusado de racismo por estudantes: Docente teria dito que "se tivesse que escolher entre médico branco ou negro, escolheria o branco" (oglobo.globo.com > por Bruno Dalvi, 05/11/2014, 8:40, atualizado em 05/11/2014, 17:09, grifo meu).

(02) Marca de uísque é acusada de culpar negros por racismo em rede social: Uma propaganda da marca de uísque Johnnie Walker sobre o Dia da Consciência Negra provocou mensagens de protesto na página da empresa no Facebook" (www1.folha.uol.com.br > por Leandro Machado, 22/11/2014, 02:00, atualizado em 23/11/2014, 15:36, grifo meu).

(03) Após ser vítima de racismo na Superliga, capitã da seleção desabafa: "Basta de ódio": A central Fabiana Claudino, do Sesi-SP e da seleção brasileira, acusou um torcedor de racismo na partida contra o Minas, na última terça-feira, pela Superliga Feminina. Segundo a atleta, um homem a chamou de "macaca” e perguntou se ela queria "banana”. (espn.uol.com. br > publicado em 28/01/2015, 10:47, atualizado em 28/01/2015, 13:25, grifo meu). 
Entretanto, neste estudo, outro acontecimento de natureza racista, recentemente veiculado pela/na mídia, configura-se como o elemento desencadeador das alegações e reflexões que serão aqui expostas, não apenas porque envolveu pessoas que atuam no maior grupo empresarial de telecomunicações do Brasil, mas, sobretudo, porque o fato em questão ocorreu no ambiente da internet e sua repercussão, mormente nas redes sociais, deu-se de um modo, a meu ver, até então inédito na sociedade brasileira, pelo menos no que tange à multiplicidade de posicionamentos assim como à duração e intensidade dos debates posteriores ao acontecido. Com efeito, apresento, abaixo, a chamada de uma matéria jornalística produzida em ambiente de mídia digital (Cf. PERNISA JÚNIOR; ALVES, 2010), que aborda o ocorrido e recupera a imagem de um de seus principais desdobramentos, o qual, do modo como vejo, é representativo (se não emblemático) das dimensões que as relações sociais e de poder alcançaram com o advento da Web 2.0.

Figura 1 - Chamada da matéria jornalística publicada no portal G1 em 03/07/2015.

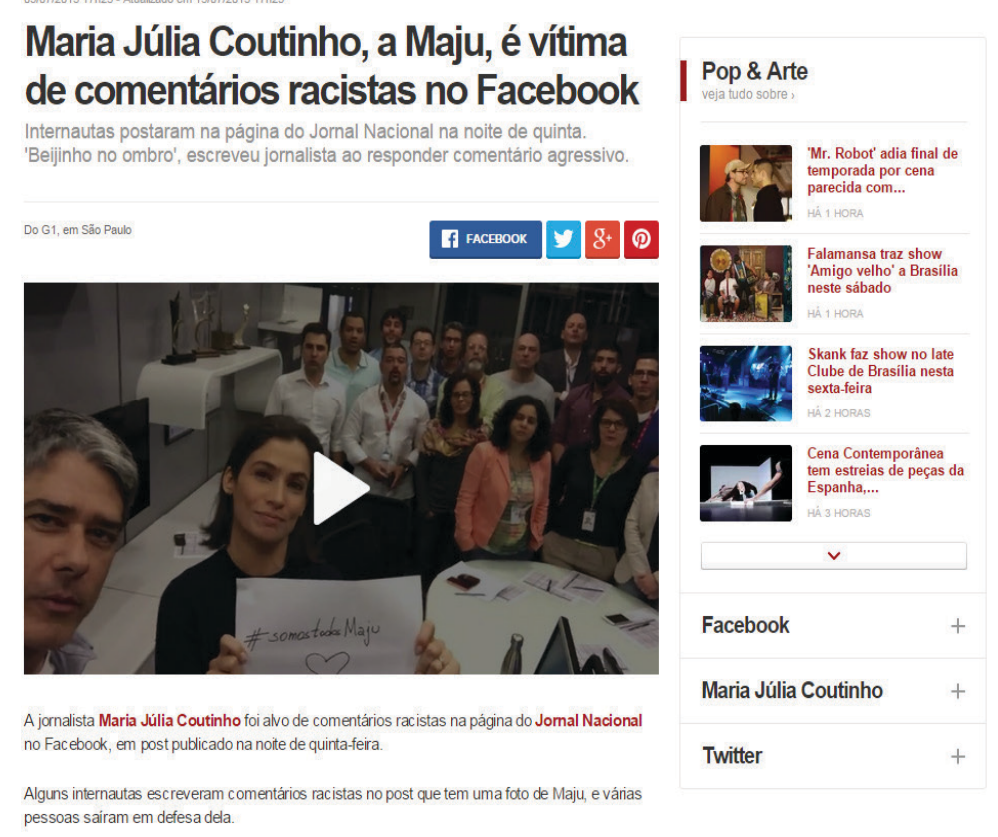

Na imagem em questão, que integra um vídeo gravado pelos jornalistas William Bonner e Renata Vasconcellos, a qual aparece exibindo em uma folha de papel a hashtag \#somostodosMaju, e que foi postado na rede social Facebook, pode-se ver, ao fundo, a equipe responsável por levar ao ar o Jornal Nacional reunida em solidariedade à jornalista Maria Júlia Coutinho, que, no dia anterior, havia sido alvo de ataques racistas também 
postados na referida rede social. Ainda, cabe aqui ressaltar que, segundo fontes não oficiais, no dia seguinte às postagens racistas, outra hashtag, intitulada \#SomosTodosMajuCoutinho, criada por internautas para manifestar apoio à jornalista, havia alcançado o topo das trending topics, designação dada aos tópicos mais comentados na rede social Twitter.

Ora, apesar de o caso em tela ter gerado fatos, em grande medida raros (ou inéditos) na mídia brasileira, como, por exemplo, a concessão de direito de resposta (ao vivo, em um telejornal exibido em rede nacional, em horário nobre) a uma jornalista negra, alvo de ataques racistas, e de que, para muitos, a decorrência mais relevante disso é a constatação da necessidade de reflexões sérias sobre como impedir que as redes sociais sejam utilizadas como espaços de ação racista. A meu ver, a oportunidade sem precedentes que se apresenta à sociedade brasileira é a percepção de outra demanda: a de saber como utilizar o potencial dessas mesmas redes não apenas como espaços de reações antirracistas, no mais das vezes pontuais, mas sobretudo como espaços propícios à vivência de uma ética da linguagem que, acredito, seja requerida não apenas para a educação das relações étnico-raciais mas também para outras contingências socioeducativas. Esses ambientes de aprendizagem autênticos e permanentemente acessíveis seriam, então, altamente favorecedores de uma formação docente inicial e continuada (mais) ampla, porque social e politicamente (mais) significativa.

Assim, com base no exposto, afirmo que a educação das relações étnico-raciais tem de estar associada a um processo de (re)qualificação da vivência sistemática daquilo que Pernisa Júnior e Alves (2010) denominam de "reversibilidade aumentada", fenômeno (hiper)midiático que, segundo esses dois pesquisadores, foi proporcionado pelo desenvolvimento da web 2.0. Nesse sentido, considerando a comunicação digital, trago alegações sobre como as (inter)ações em redes sociais podem (e devem) ser, mediante a apropriação de determinadas epistemologias, resgatadas da fugacidade que, via de regra, caracteriza muitas das práticas de letramento digital (Cf. MOITA-LOPES, 2012), para serem convertidas, por professoras(es) do Ensino Básico, em emancipação e autonomia, requisitos fundamentais que a implementação da Lei Federal 10.639/2003 requer dessas(es) profissionais, a despeito das condições adversas em que muitas(os) delas(es) são/ foram formadas(os) e atuam.

Portanto, do modo como vejo, este estudo é concebido em função da necessidade de se reconhecer a relevância do processo anteriormente mencionado para a formação de professoras(es) que sejam capazes de e estejam dispostas(os) a contribuir para a educação das relações étnico-raciais. Isso remete ao fato de que aquelas(es) que detêm certos conhecimentos decorrentes de pertencimento institucional e formação profissional estamos moralmente obrigadas(os) a refletir sobre e a apontar possíveis formas de 
Alegações sobre mídia digital no âmbito da lei federal 10.639/2003, Consciência linguística crítica e formação docente

legitimar e operacionalizar os mecanismos legais criados para a redução das injustiças advindas das desigualdades raciais.

Por conseguinte, em razão da transdisciplinaridade que caracteriza este estudo e, sobretudo, das dimensões social e política que o demandam, utilizo uma abordagem crítico-discursiva da linguagem (Cf. FAIRCLOUGH, 2009; CHOULIARAKI e FAIRCLOUGH, 1999), pois a adoção da perspectiva da Análise Crítica do Discurso (doravante ACD) possibilita associar aspectos da comunicação digital, da educação das relações étnico-raciais e dos letramentos sociais (Cf. STREET, [1995] 2014), relacionando-os, por seu turno, à formação de professoras(es).

Findas as explanações introdutórias, passo, agora, às próximas seções, dedicadas a apresentar as alegações que norteiam este breve estudo, o qual integra um projeto mais amplo de pesquisa e extensão que vem sendo pensado no Departamento de Letras da Universidade Federal de São Paulo.

\section{Alegações sobre a Lei Federal 10.639/2003}

Segundo Gomes (2007), o contexto histórico, social, cultural e político que explica e caracteriza o racismo brasileiro tem como especificidades os seguintes aspectos: a longa duração do período escravagista, a colonização e dominação política e cultural de determinados grupos sociais e étnico-raciais, a resistência de negros e negras à escravidão, a tensão que marcou a abolição e as várias formas de negociação envolvidas nesse processo, a criação de um regime republicano que desprezou a demanda pela integração dos(as) negros(as) libertos(as), o autoritarismo e golpes militares que caracterizaram a república, a ação dos movimentos sociais, buscando o retorno da democracia ao Estado e à sociedade civil, na década de 1980, processo ao qual se soma o neoliberalismo e a globalização capitalista.

Neste contexto, a mencionada autora destaca o papel político primordial que teve e tem o Movimento Negro, pois este, além de denunciar a opressão e exploração que marcam as injustiças sofridas pela população negra brasileira, tem reivindicado que o Estado saia de sua posição de neutralidade em relação à desigualdade racial e adote políticas de ação afirmativa e, ainda, intervenha dentro do próprio Estado para criar instâncias políticas e intelectuais progressistas, inclusive no governo federal. Gomes também acredita que mediante a superação do racismo e da desigualdade racial seja possível alcançar transformações éticas e solidárias que abranjam a sociedade como um todo, favorecendo, assim, tanto a efetivação da justiça social e o pleno exercício da cidadania, quanto o direito à diversidade, pois, segundo ela, esse processo poderá propiciar uma reeducação social e cultural dos brasileiros no que tange à diversidade. 
Gomes (2007) acrescenta, ainda, a necessidade da criação de oportunidades para que tanto negros quanto brancos possam estabelecer um contato real com as diferenças, contudo, pautado pela igualdade e pela cidadania, e que, segundo ela, ultrapasse o aspecto discursivo do politicamente correto, alegação da qual compartilho e que, do modo como vejo, pode ser associada à demanda por uma educação linguística.

Essa educadora enfatiza que, especialmente após a constatação oficial das denúncias do Movimento Negro $^{2}$ e da $3^{\text {a }}$ Conferência Internacional contra o Racismo, a Discriminação Racial, a Xenofobia e Formas Correlatas de Intolerância, realizada em Durban, África do Sul, em 2001, ações concretas foram realizadas pelo Estado brasileiro, sobretudo no nível federal, dentre as quais se destaca a promulgação da Lei Federal 10.639, sancionada pelo presidente da República, Luiz Inácio Lula da Silva, em 9 de janeiro de 2003 (e alterada posteriormente pela Lei Federal 11.645/2008), tornando obrigatório o ensino da temática História e Cultura Afro-brasileira nos estabelecimentos de Ensino Básico.

Com base na referida lei, o Conselho Nacional de Educação (CNE) criou as Diretrizes Curriculares Nacionais para a Educação das Relações Étnico-Raciais e para o Ensino de História e Cultura Afro-brasileira e Africana, que constam do Parecer do Conselho, CNE/CP003/2004 e CNE/ CP Resolução 1/2004. Outro ponto de destaque refere-se ao fato de a Lei Federal 10.639/2003 alterar a Lei de Diretrizes e Bases da Educação Nacional, Lei Federal 9394/1996, fazendo desta a primeira LDBEN a introduzir efetivamente a temática das relações raciais em seu texto (Cf. GOMES, 2007).

A meu ver, são de ordem social e política mas, igualmente, didático-pedagógica, as alegações de Gomes (2007), porque, em grande medida, remetem a certas determinações contidas nas Diretrizes Curriculares engendradas a partir da promulgação da Lei Federal 10.639/2003, a saber:

- Incentivo, pelos sistemas de ensino, a pesquisas sobre processos educativos orientados por valores, visões de mundo, conhecimentos afro-brasileiros [...] com o objetivo de ampliação e fortalecimento de bases teóricas para a educação brasileira. (BRASIL, 2004, p. 24).

Portanto, a presença da educação das relações étnico-raciais no sistema educacional brasileiro revela-se pertinente, tanto em virtude da especificidade desse tipo de relações sociais e da necessidade de intervenção do Estado nos seus pontos tensivos, quanto em razão da demanda por subsídios didático-pedagógicos para a sua consecução. Em relação a essa demanda, Gomes (2005, p. 60) afirma que “[...] existe uma produção mais consistente sobre a temática racial que deve ser incorporada como fonte de estudo individual e coletivo dos(as) educadores(as).”

\author{
${ }^{2}$ Gomes refere-se à \\ pesquisa realizada \\ pelo Instituto de \\ Pesquisa Econômica \\ Aplicada (IPEA), em \\ 1999, que revelou um \\ contexto altamente \\ preocupante em \\ termos da relação \\ entre a escolarização \\ dos negros \\ brasileiros e as \\ desigualdades raciais, \\ recomendando, na \\ época, que medidas \\ urgentes fossem \\ tomadas.
}


Alegações sobre mídia digital no âmbito da lei federal 10.639/2003, Consciência linguística crítica e formação docente

Contudo, há também a demanda pela incorporação de determinadas epistemologias que possibilitem problematizar a temática racial a partir dos ambientes virtuais propiciados pela comunicação digital, a qual se faz presente, de modo ubíquo, no cotidiano da maior parte da população brasileira (e mundial). Com efeito, a próxima seção será dedicada a apresentar algumas alegações nesse sentido.

\section{Alegações sobre mídia digital}

Quando se pensa em relações étnico-raciais, parece razoável que o ponto principal a ser considerado não deva ser apenas a expressão de identidades, mas a consciência de que não deve haver dissociação entre o que as pessoas precisam fazer com a linguagem para construírem (ou manterem) algumas de suas identidades e o que elas precisam fazer (ou não) aos outros com a linguagem para alcançarem esse objetivo, cisão que não coaduna com a ideia de educação das relações étnico-raciais.

Soma-se ao exposto o fato de que, atualmente, para além da oralidade, as novas Tecnologias da Informação e da Comunicação (TIC) e, em especial, a internet, mormente após o advento da Web 2.0, têm possibilitado às pessoas "[...] novas condições técnicas e socioculturais para a ampliação de práticas comunicativas no mundo digital [...]” (PINHEIRO, 2012, p. 248), fato que colabora para o reconhecimento de uma concepção multimodal de linguagem, calcada não apenas em elementos verbais mas também em gestos, cores, sons, imagens e movimentos.

Assim, as noções de vivência e interação podem ser não apenas consideravelmente aumentadas pelas TIC, mas sobretudo entendidas como social, histórica e culturalmente cruciais para os processos de ensino-aprendizagem e, neste estudo, fundamentais para se pensar uma formação inicial e continuada de professores que seja calcada no diálogo intercultural e multirracial. Nesse sentido, esclareço que, aqui, denomino de mídia digital aquela cujos usuários (leitores/escritores) operam a partir da Web 2.0 (Cf. PERNISA JÚNIOR; ALVES, 2010).

Associa-se a tudo isto o fato de que, na perspectiva dos estudos sobre mídia digital, os conceitos de interação, reversibilidade e vocalização, a meu ver, propiciam que se pense em formas de resistir ao processo de colonização de certas práticas letradas pelo letramento escolar (Cf. STREET, [1995] 2014), o qual está relacionado ao abandono de formas de aprendizagem tradicionalmente baseadas na oralidade e na narrativa e, por isso mesmo, relevantes para a constituição das identidades de indivíduos e grupos sociais.

Na perspectiva midiática, diferentemente dos estudos da linguagem, o conceito de interação, de modo geral, caracteriza sites e portais jornalísticos que são voltados, principalmente, para os comentários de leitores e 
para as respostas destes a uma bateria de perguntas, cujos resultados serão, posterior e automaticamente, tabulados, não implicando, necessariamente, reversão de posições. Ou seja, o leitor é demandado a se posicionar, porém não tem a possibilidade de interferir no mapeamento dos sentidos, o que é uma prerrogativa dos responsáveis pela manutenção do site.

A reversibilidade, por sua vez, somente é possível, sobretudo em maior grau, se o outro-leitor tiver a possibilidade de reconstituir a produção de sentidos daquilo que foi veiculado ou comentado. Esse processo dinâmico e ativo, no entanto, não é, geralmente, propiciado pelos portais, o que obriga os leitores a levarem as notícias para outros ambientes (fóruns, blogs e redes sociais) onde podem ter acesso a uma reversibilidade aumentada e, dessa forma, intervir na própria textualidade, semelhantemente ao que ocorre nas práticas letradas (anteriormente mencionadas) que se ancoram na oralidade e na narrativa, em contextos familiares e profissionais.

Ora, a web vem produzir deslocamentos importantes na rede de memória. Ela reconfigura o interdiscurso - o conjunto de discursos disponíveis numa conjuntura dada -, tonificando sentidos até então apenas adjacentes na velha mídia, fazendo reverberar no espaço público constituído pela rede aquilo que não era "relevante” dizer/ouvir/escrever/ler. Além disso, vocaliza sentidos [conceitualmente, vocalização opõe-se a silenciamento], discursos e atores proscritos na velha mídia. Talvez a rede não constitua, por si mesma, novos discursos, mas, ao dar espaço para novas formulações, acaba por produzir deslocamentos na ordem da memória, ao tornar outros discursos disponíveis para os sujeitos. (PERNISA JÚNIOR; ALVES, 2010, p. 112).

Essa citação remete, de algum modo, a formas mais amplas de aprendizagem, que possibilitam às pessoas a vivência e a partilha de outros discursos e identidades, porém de uma forma mais autêntica e, em grande medida, não necessariamente vinculada ao contexto escolar (ou escolarizado), porque não tem como ponto de partida e de chegada as práticas sociais localizadas exclusivamente nesse espaço institucional, mas todos os contextos sociais e institucionais em que os indivíduos circulam (física ou virtualmente) e vivem suas vidas.

Consoante com essas afirmações, Moita-Lopes (2012) aponta que nas práticas de letramentos digitais, mas também em outras, são os grupos de participantes que sancionam as formas de construir significados, o que revela a natureza social e relacional de tais práticas, bem como os modos de legitimar a identificação grupal e, igualmente, a exclusão dos indivíduos, o que coloca em evidência, sobretudo, a importância da explicitação de regras operacionais, de aprender a partilhar conhecimento, dar opiniões, demonstrar pertencimento, engajar-se identitariamente, dentre outros requisitos.

Neste ponto, é possível alegar que as formas de ação e participação social oferecidas pela mídia digital podem favorecer a formação de 
Alegações sobre mídia digital no âmbito da lei federal 10.639/2003, Consciência linguística crítica e formação docente

professoras(es) para a educação das relações étnico-raciais justamente porque "[...] a ênfase nas relações entre as pessoas [...] nos coloca de frente a possibilidades outras de viver a vida social, com consequências marcantes e inovadoras para nossas próprias performances identitárias [...]”. (MOITA-LOPES, 2012, p.214).

Entretanto, a ênfase nas relações entre as pessoas, a meu ver, não prescinde de critérios éticos claros, que oportunizem uma requalificação das experiências de multiculturalidade vivenciadas pelas(os) professoras(es), porque as experiências propiciadas pela reversibilidade aumentada, na internet, ocorrem, em geral, pautadas pelas instâncias de poder midiático (grandes empresas de telecomunicação) e, portanto, no mais das vezes, têm como parâmetros as ações e atitudes de pessoas detentoras de prestígio social e econômico (jornalistas, artistas), o que dificulta o engajamento das(os) (futuras/os) docentes em processos sociais mais longos e significativos, os quais, por sua vez, favoreceriam intervenções sociais (individuais e/ou coletivas). Ou seja, a simples aprovação ou desaprovação das ações e atitudes de figuras públicas não chega a ser uma ação social relevante! E não chega, tampouco, a colaborar para uma independência de pensamento e para a (re)construção de identidades sociais requeridas para o trabalho social das(os) docentes.

“A constatação de que podemos estar diante de 'sujeitos formatados', com uma produção-leitura precondicionada pelo espetacular e pelo desejo de consumo, não deve ser minimizada”. (PERNISA JÚNIOR; ALVES, 2010, p. 114). Concordando com essa alegação, busco, na seção seguinte, apresentar uma epistemologia que poderá ser útil à formação docente no âmbito da Lei Federal 10.639/2003 e ao balizamento da reversibilidade aumentada.

\section{Alegações sobre consciência linguística crítica e formação docente}

Uma afirmação de Chouliaraki e Fairclough (1999) sobre os usos linguísticos na modernidade tardia é, em particular, significante neste estudo, a saber: apesar das práticas serem altamente homogeneizadas, a agência pode expressar reflexividade, capacidade para usar o conhecimento sobre a vida social para transformá-la. Significa dizer que os agentes podem criar estratégias discursivas, nelas incluídas a aplicação consciente de conhecimentos sobre práticas de linguagem, para mudar certas práticas de linguagem, como parte de estratégias mais amplas de mudança. Essa afirmação coloca em pauta o fato de que o discurso pode ser um recurso mobilizado para a mudança social.

Do modo como vejo, é possível encontrar indicações sobre tal recurso na obra Critical Language Awareness, publicada por Norman Fairclough, em 1992. Nela o autor apresenta em detalhes sua concepção de Consciência 
Linguística Crítica (CLC) e explica que esta pressupõe e se constrói sobre um campo que possui inúmeras denominações, a saber: estudo crítico da linguagem, linguística crítica ou análise crítica do discurso.

Já na introdução da referida obra, Fairclough esclarece que o termo consciência linguística tem sido usado desde o início dos anos 1980 para se referir, especificamente, àquilo que era defendido por um grupo de educadores e linguistas aplicados como um novo componente de consciência da linguagem no currículo das escolas britânicas. Além disso, a noção de consciência linguística remete não apenas às escolas, mas, inclusive, a outros domínios da educação informal.

No que concerne à relação entre educação linguística e mudança social, Fairclough diz acreditar que a CLC tornou-se um pré-requisito para uma cidadania democrática efetiva e, portanto, um direito dos cidadãos, em especial para o desenvolvimento da cidadania das crianças no sistema educacional. Segundo ele, se as relações de poder são cada vez mais exercidas implicitamente pela/na linguagem, e se as práticas de linguagem são, conscientemente, controladas e inculcadas; então, uma linguística que se contenta em descrever as práticas de linguagem sem tentar explicá-las, nem em relacioná-las às relações sociais e de poder que a elas subjazem, parece estar falhando na sua responsabilidade para com os aprendizes. De maneira mais contundente, ele afirma:

As pessoas não podem ser cidadãos efetivos numa sociedade democrática se a sua educação as poda da consciência crítica de elementos fundamentais do seu ambiente físico ou social. Se estamos comprometidos com uma educação que forneça recursos para a cidadania, a consciência crítica das práticas de linguagem de uma dada comunidade discursiva é um direito. (FAIRCLOUGH, 1992, p. 6).

Fairclough (op. cit.) procura caracterizar a CLC, resumidamente, em torno de cinco proposições teóricas de base crítico-discursiva:

1. A linguagem como uso - discurso - molda e é moldada pela sociedade.

2. O discurso ajuda a constituir (e modificar) o conhecimento e seus objetos, as relações sociais e a identidade social.

3. O discurso é moldado pelas relações de poder e investido com ideologias.

4. A moldagem do discurso é uma faceta das lutas pelo poder.

5. A CLC presta-se a mostrar como a sociedade e o discurso moldam um ao outro.

Nesse sentido, a CLC, segundo Fairclough (1992), justifica-se pelo argumento de que escolas dedicadas a uma pedagogia crítica devem suprir os aprendizes com o entendimento de problemas que não podem ser resolvidos apenas nas/pelas escolas; e com os recursos para se engajarem, caso 
queiram, em lutas multifacetadas mais duradouras em diversos domínios sociais, inclusive na educação. Embora isso não signifique que a CLC não se ocupe de questões como as dimensões especificamente linguísticas do fracasso educacional.

A meu ver, sobretudo essa última afirmação remete à possibilidade de que a inclusão de um componente de CLC na formação inicial e continuada de professoras(es) favoreça que estas(es) considerem a existência da demanda por uma educação linguística na educação das relações étnico-raciais. Por conseguinte, também seria possível levá-las(os) a (re)pensar o papel do discurso em situações de abuso de poder que, via de regra, exigem o empoderamento das pessoas subjugadas e desrespeitadas em seus direitos fundamentais, a começar por elas(es) próprias(os).

E, se assim for, um(a) licencia(n)do/a em qualquer área do conhecimento teria recursos discursivos ${ }^{3}$ para agir não apenas em conflitos relacionados à categoria profissional a que pertence(rá), mas também àqueles que envolvem relações de gênero, étnico-raciais, dentre outros, seja no contexto escolar seja noutros contextos, inclusive virtuais.

Essas afirmações remetem a outras ainda mais cruciais e abrangentes para a formação inicial e continuada das(os) professoras(es) e, mormente, para a realização de seu trabalho social no âmbito da Lei Federal 10.639/2003. Por exemplo, nesse sentido pode-se alegar que a CLC pode fornecer condições para um empoderamento sociocognitivo da(o) (futura/o) docente, pois conta com atividades que propiciam a construção de determinadas cognições sociais (conhecimentos, opiniões, posturas e representações sociais) que lhes dão condições para melhor dimensionar, em função do contexto sócio-político-cultural brasileiro e das relações de poder, as necessidades didático-pedagógicas das(os) alunas(os). Essa epistemologia também seria demandada porque é capaz de fornecer critérios que, de modo mais abrangente, respaldam e pautam o trabalho social docente, isto é, amparam mais fortemente ações, decisões e atitudes, assim como as responsabilidades éticas e morais delas decorrentes.

Entretanto, uma mudança de maior amplitude social pode exigir dos agentes envolvidos o conhecimento e, em especial, a manutenção de determinadas práticas discursivas institucionalizadas, disso dependendo, inclusive, o engajamento na ação transformadora e a legitimidade dos agentes, o que remete às alegações de Moita-Lopes (2012) acerca das práticas de letramentos digitais.

Deste modo, o discurso enquanto recurso mobilizado é também um instrumento de identificação e avaliação de um perfil desejado para a ação social, ou seja, um dispositivo a serviço do controle, em uma relação assimétrica, utilizado pela parte detentora de poder para localizar, empoderar e credenciar um agente a agir em nome desta. Por outro lado, Fairclough (2009) refere-se ao fato de a Análise Crítica do Discurso ser considerada

\author{
${ }^{3}$ A principal \\ propriedade dos \\ recursos discursivos \\ (ou semióticos) é, \\ justamente, articular \\ a dimensão material \\ (física) à dimensão \\ sociocultural, \\ mediante certos \\ usos da linguagem, \\ isto é, determinados \\ conhecimentos \\ discursivos e práticas \\ discursivas. (Cf. \\ LÍRIO, 2012).
}


crítica em função de objetivar a contribuição para a abordagem do que ele denomina de erro social, isto é, a injustiça, a desigualdade, a falta de liberdade, dentre outros.

Portanto, essas alegações, a meu ver, aproximam a abordagem crítico-discursiva, a formação docente inicial e continuada, e a reversibilidade aumentada, somente quando se leva em conta o fato de que as pessoas têm a capacidade de perceber a internet como ponto de entrada semiótico para a intervenção social coletiva, visando eliminar erros sociais que, há séculos, vêm assolando, sobretudo, certos grupos étnico-raciais.

Concluo esta seção com uma última, porém não menos relevante e emblemática alegação, a saber:

[...] professores habilidosos podem facilitar perspectivas críticas em linguagem apropriada e formas comunicativas com a mesma rapidez com que os tradicionalistas conseguem ensinar gêneros, níveis, conteúdos e habilidades dentro de um conceito conservador de letramento. A introdução da Consciência Linguística Crítica e do letramento como prática social crítica pode, acredito, facilitar o processo. Introduzi-los em sala de aula não é um luxo, mas uma necessidade. (STREET, [1995] 2014, p.155).

\section{Conclusão}

Este breve artigo, conforme mencionei no início, trata-se de um mero exercício reflexivo cujo principal objetivo foi (re)pensar a formação inicial e continuada das(os) professoras(es) frente às permanentes demandas da sociedade brasileira, dentre as quais destaco a necessidade de uma efetiva educação das relações étnico-raciais, conforme exigido pela Lei Federal $10.639 / 2003$. Nesse sentido, creio que as epistemologias aqui apresentadas (e, talvez, já conhecidas) possam contribuir, substancialmente, fornecendo elementos para certas mudanças curriculares, as quais se revelam necessárias para que o trabalho social dessas(es) profissionais seja realizado de modo significativo. Isto é, para que possam interferir positivamente na sua própria qualidade de vida e na de suas(seus) alunas(os), pois planos de vida podem ser produzidos, modificados e (infelizmente) interrompidos, mesmo em ambientes virtuais.

É, portanto, a meu ver, urgente que professoras(es) tenham, em sua formação inicial e continuada, recursos que favoreçam a percepção das relações de poder e a necessidade de resistência à dominação de gênero, étnico-racial e profissional que, em geral, apresentam-se imbricadas e, por isso mesmo, imperceptíveis e quase que imutáveis. Quase! 
Alegações sobre mídia digital no âmbito da lei federal 10.639/2003, Consciência linguística crítica e formação docente

\section{Referências}

BRASIL. Lei $\mathrm{n}^{\mathbf{0}} \mathbf{1 0 . 6 3 9}$, de 9 de janeiro de 2003. Altera a Lei $\mathrm{n}^{\circ}$ 9.394, de 20 de dezembro de 1996, que estabelece as diretrizes e base da educação nacional, para incluir no currículo oficial da Rede de Ensino a obrigatoriedade da temática "História e Cultura Afro-Brasileira", e dá outras providências. Brasília, DF, 2003.

- Ministério da Educação, Diretrizes Curriculares Nacionais para a Educação das Relações Étnico-Raciais..., Brasília, DF, 2004.

Ministério da Educação/Fundo Nacional de Desenvolvimento da Educação/Conselho Deliberativo, Resolução/CD/FNDE No 14, de 28 de abril de 2008. Brasília, DF, 2008.

Ministério da Educação/Secretaria de Educação Continuada, Alfabetização, Diversidade e Inclusão. Disponível em: < http://portal. mec.gov.br/index.php?option $=$ com_content\&view=article\&id=290\&Ite mid=816>. Acesso em: 1 out. 2011.

Lei no 13.005, de 25 de junho de 2014. Aprova o Plano Nacional de Educação - PNE e dá outras providências. Brasília, DF, 2014.

CHOULIARAKI, Lilie; FAIRCLOUGH, Norman. Discourse in late modernity: rethinking critical discourse analysis. Edinburgh: Edinburgh University Press, 1999.

FAIRCLOUGH, Norman. (Ed.). Critical language awareness. London: Longman, 1992.

- A dialectical-relational approach to critical discourse analysis in social research. In: WODAK, Ruth; MEYER, Michael (Orgs.). Methods of critical discourse analysis. $2^{\text {nd }}$ ed. Los Angeles, Londres, Nova Délhi, Singapura, Washington: Sage, 2009. p. 162-187.

GOMES, Nilma Lino. Alguns termos e conceitos presentes no debate sobre relações raciais no Brasil: uma breve discussão. In: Educação antiracista: caminhos abertos pela Lei Federal $n^{0} \mathbf{1 0 . 6 3 9 / 0 3}$. Secretaria de Educação Continuada, Alfabetização e Diversidade. - Brasília: Ministério da Educação, Secretaria de Educação Continuada, Alfabetização e Diversidade, 2005. p. 39-62.

Diversidade étnico-racial e educação no contexto brasileiro: algumas reflexões. In: GOMES, Nilma Lino (Org.). Um olhar além das fronteiras: educação e relações raciais. Belo Horizonte: Autêntica, 2007. p. 97-109.

LÍRIO, Carlos José. Ações afirmativas e recursos discursivos: a representação dos atores sociais na dimensão extensionista de projetos educacionais selecionados para o Programa UNIAFRO 
em 2008. 2012. 180p. Tese (Doutorado em Linguística do Texto e do Discurso). Universidade Federal de Minas Gerais, Belo Horizonte, 2012.

MOITA-LOPES, Luiz Paulo da. O novo ethos dos letramentos digitais: modos de construir sentido, revolução das relações e performances identitárias fluidas. In: SIGNORINI, Inês; FIAD, Raquel Salek (Orgs.). Ensino de língua: das reformas, das inquietações e dos desafios. Belo Horizonte: Editora UFMG, 2012.

PERNISA JÚNIOR, Carlos; ALVES, Wedencley. Comunicação digital: jornalismo, narrativas, estética. Rio de Janeiro: Mauad X, 2010.

PINHEIRO, Petrilson Alan. Práticas colaborativas de escrita por meio de ferramentas da internet: Ressignificando a produção textual no contexto escolar. In: SIGNORINI, Inês; FIAD, Raquel Salek (Orgs.). Ensino de língua: das reformas, das inquietações e dos desafios. Belo Horizonte: Editora UFMG, 2012.

STREET, Brian V. Letramentos sociais: abordagens críticas do letramento no desenvolvimento, na etnografia e na educação. Tadução Marcos Bagno. 1. ed. São Paulo: Parábola, [1995] 2014. 